\title{
ANTROPOLOGIA INTERPRETATIVA E ETNOGRAFIA NA PESQUISA SOBRE ESCOLARIZAÇÃO EM AMBIENTE HOSPITALAR
}

\author{
INTERPRETATIVE ANTHROPOLOGY AND ETHNOGRAPHY ON THE \\ RESEARCH OF SCHOOLING IN HOSPITAL ENVIRONMENT
}

\author{
Fernando Lionel Quiroga ${ }^{1}$ \\ Universidade Estadual de Goiás \\ ORCID:https://orcid.org/0000-0003-4172-2002
}

\section{RESUMO}

Neste artigo, discute-se sobre a possibilidade etnográfica, na perspectiva da antropologia interpretativa, como recurso metodológico para investigar a escolarização em ambiente hospitalar. Um dos motivos que nos leva a refletir sobre essa estratégia deve-se à escassez da produção de trabalhos realizados nessa direção, cuja consequência abre uma lacuna e uma demanda na interpretação dos sentidos relativos a essa experiência. Nossa compreensão é de que o fenômeno da escolarização hospitalar é um cruzamento dos campos da Saúde e da Educação, que se desdobra em suas diversas dimensões: jurídica, estrutural, epistemológica, profissional e humana e que compõe um espaço sui generis de relações humanas.

Palavras-chave: Escolarização hospitalar. Etnografia. Antropologia interpretativa. Direito.

\section{INTRODUÇÃO}

O propósito central deste artigo é de compreender a experiência da escolarização hospitalar a partir da pesquisa etnográfica. Esse interesse se deve aos sentidos provenientes do contexto onde dois campos historicamente consolidados se fundem: a Educação e a Saúde.

De modo geral, tem-se dado ênfase à importância do direito à educação de crianças gravemente enfermas, com destaque para os aspectos relativos à formação profissional específica, os dispositivos legais que regulam esse segmento, as questões psicológicas, dentre outros. A maior parte desses estudos tem-se concentrado mais em tais desdobramentos do que em seus fundamentos ou suas formas de funcionar em determinada realidade cotidiana. Estudos recentes sobre a temática, que sugerem diversas questões decorrentes desse cruzamento epistemológico, na última década, tomaram como objeto, para citar alguns exemplos, a compreensão das diversas propostas de escolarização hospitalar (FERREIRA, et. al., 2015); o problema da qualificação de profissionais especializados (XAVIER, et. al. 2013); a urgência de

\footnotetext{
1 Fundamentos da Educação - Universidade Estadual de Goiás, UEG. E-mail: quirogapesquisa@hotmail.com
} 
políticas públicas relativas à escolarização hospitalar (Saldanha, et. al., 2013) e a estratégia da escolarização hospitalar como noção importante de cuidado (HOLANDA \& COLLET, 2012) etc.

Embora Zardo (2006) tenha trazido para debate a etnografia, em uma monografia intitulada $\mathrm{O}$ processo de gestão educacional da classe hospitalar do Hospital Universitário de Santa Maria: uma abordagem etnográfica, seus estudos posteriores, com a implantação da classe hospitalar em Santa Maria (RS), não foram representativos sobre esse recurso no sentido clássico do conceito, ou seja, não tiveram como pressuposto metodológico captar os sentidos sociais e culturais decorrentes da classe hospitalar, mas fundamentar uma concepção alinhada às demandas que a realidade impõe.

Deve-se ressaltar que as pesquisas desses autores não estão concluídas, e é natural que outras dimensões do fenômeno tenham sido implementadas ao longo da trajetória investigativa por cada um deles. Há, portanto, uma lacuna quanto à compreensão desse fenômeno no sentido antropológico, isto é, como compreender as relações sociais que se estabelecem no interior do hospital nessa situação.

Neste trabalho, discute-se sobre a possibilidade de se introduzir a abordagem etnográfica na experiência da escolarização hospitalar. Essa discussão consiste em problematizar a estratégia metodológica do projeto de Doutorado que venho desenvolvendo no Instituto de Oncologia Pediátrica (IOP) GRAACC - Grupo de Apoio ao Adolescente a Criança com Câncer, de São Paulo, desde 2015.

\section{O PESO DA HISTÓRIA: A FORMA ESCOLAR}

A escolarização hospitalar pode ser caracterizada pela marca que o direito à educação - e seu caráter de obrigatoriedade - imprime ao aluno doente e a relação que a partir daí se estabelece com o direito à saúde e ao con vívio no espaço hospitalar. Dessa fonte se origina o debate que resulta no cruzamento das duas instituições: educação e saúde - ou, mais especificamente, a escola e o hospital - e suas implicações na realidade de trabalho onde a ação docente se materializa.

Trata-se, portanto, de um contexto específico, distinto do que verificamos na forma escolar convencional, marcado por uma simultaneidade de alunos em um tempo racionalizado e fragmentado em disciplinas, e por uma disposição de recursos materiais que orientam a ação didática do professor. Diferentemente dessa estrutura, a escolarização hospitalar é uma experiência cuja ação é planejada a partir da relação que 
o professor estabelece com o aluno em determinada situação contextual, por exemplo, no momento em que o aluno recebe uma medicação intravenosa ou enquanto aguarda a administração de um protocolo médico. A escolarização, aqui, adequa-se aos tempos intermediários entre as diversas situações inerentes ao tratamento, não dispõe de um tempo exclusivo para ela, já que o corpo da criança ou do adolescente, nesse período, obedece à lógica do tratamento e, por conseguinte, da racionalidade médica, que é autorizada na forma do direito à saúde. $\mathrm{O}$ direito à educação, por outro lado, aparece como uma justaposição do direito à saúde. Do ponto de vista teórico, uma questão de ordem epistemológica se impõe com força total: a tradição da forma escolar tradicional, que traz em seu arquétipo constitutivo a ideia de uniformização, isto é, o indivíduo, nesse cenário, representa uma ideia elitista da educação. Com a universalização dos acessos e na medida em que implementa, primeiramente com São João Batista de La Salle $^{2}$ e, depois, com Joseph Lancaster ${ }^{3}$, a forma do ensino simultâneo, a escola republicana destitui do cenário escolar a abordagem do ensino individualizado, ideia consagrada pelo pensamento rousseauniano ${ }^{4}$. Em outras palavras, a educação passa a ser compreendida como um projeto coletivo, que se inscreve na dimensão política.

Assim, se os desafios da escolarização hospitalar incluem questões técnicas e pedagógicas, que estabelecem uma interface entre a saúde e a educação, que passam também pelo direito e pela formação dos profissionais envolvidos nesse processo e contemplam o savoir-faire relativo a essa situação, deve-se compreender que questões de ordem epistemológica, da constituição do campo da saúde e da educação são mais que emergentes, sobretudo porque, nessa fusão, adquirem uma conotação singular. Embora a escolarização hospitalar conserve valores da escola convencional, do modelo que se desenvolveu ao longo de quase dois séculos, trata-se, todavia, de uma experiência escolar em cujo eixo norteador há uma distinção radical sobre a forma escolar tradicional: a simultaneidade no ambiente hospitalar não tem sentido algum.

Para pensar na questão, devemos ter em mente que é o sentido coletivo que organizou e formou o modelo da escola convencional. Tal ideia, nesse argumento, não pode ser enquadrada em um relativismo cômodo, mas compreendida como a pedra

\footnotetext{
${ }^{2} \mathrm{O}$ francês, João Batista de La Salle (1651-1719), foi um sacerdote e pedagogo que consagrou sua vida à formação de professores destinados ao trabalho com crianças pobres. A aula, a partir de La Salle, passou a ser compreendida como um espaço em que a experiência do ensino-aprendizagem destinava-se a uma simultaneidade de alunos, concepção oposta ao modelo elitista que vigorava antes desse período.

${ }^{3}$ Joseph Lancaster (1778-1838) foi um quaker inglês e pedagogista que inovou a educação pública com um método capaz de ensinar um mesmo conteúdo a uma simultaneidade de alunos, que, mais tarde, foi difundido como método lancasteriano.

${ }^{4}$ Cf. Emílio ou da Educação, de Jean-Jacques Rousseau, escrito entre 1757 e1762.
} 
fundamental por excelência, cujo sentido atrai as demais para seu eixo de orientação. Um só exemplo nos é suficiente para confirmar esse argumento: o de que não se pode pensar no quadro e no giz sem que se tenha pensado na concepção de simultaneidade de uma escola destinada às massas. A escola do modelo republicano implica uma ideia que é crucial: a simultaneidade representa melhor o ideal de cidadania. Alinhado a esse contexto, o debate sobre esse período se abre de modo intenso para se discutir sobre a relação entre o indivíduo e a sociedade, natureza e cultura, universal e particular, público e privado etc. Uma diversidade de autores da Sociologia e da Antropologia, como Titiev (1966), Durkheim (1973), Lévi-Strauss (1975) e Elias (1990), comprovam esse argumento cujo período ocupou, com mais ênfase, a segunda metade do Século XX.

Do ponto de vista do ideal republicano, a noção de homem é constitutiva da noção de cidadania. De modo geral, cidadania implica a vida a partir dos direitos relativos ao cidadão, isto é, de sua participação na vida política da sociedade. Vejamos, no próximo tópico, de que modo tais aspectos se fundem à constituição da escola moderna e como se colocam como questões elementares para se compreender essa problemática.

\section{ESCOLARIZAÇÃO HOSPITALAR: A DILUIÇÃO DA SIMULTANEIDADE E O RETORNO DO INDIVÍDUO}

Dentre as funções da teoria, talvez a mais importante sobre a aplicação social seja a de refletir sobre os modos de vida de determinado contexto, verificar suas contradições e principais problemas e apontar suas estruturas e seus pontos de convergência e de divergência no confronto com dada realidade. A Sociologia e a Antropologia são disciplinas expoentes que expressam bem tais características do pensamento teórico. Ambas são coincidentes com o momento histórico em que se instaura o sentido de cidadania sobre o de indivíduo, e ambas têm como eixo norteador as razões sociais e culturais, portanto, do senso comum, como elementos fundantes de toda a reflexão posterior. Essas teorias representam um sentido de superação, embora esse talvez não seja o termo mais adequado, do pensamento aristocrático e individualista cujo apogeu se deu com a Crítica da Razão Pura, de Emanuel Kant.

Essa perspectiva implica a desconfiança de que a noção de indivíduo passa por um momento de crise, provavelmente derivada desse movimento iniciado em fins do Século XIX. Notadamente, podem-se observar indícios dessa crise em situações da 
sociedade contemporânea em que a noção de indivíduo é convocada. Exemplo disso são as tensões que envolvem grupos minoritários que hoje compõem o tema 'diversidade'. O problema da inclusão, por exemplo, constitui-se, fundamentalmente, do confronto entre os indivíduos e a sociedade. O grande desafio da teoria atual consiste em resolver essa difícil tensão, sobretudo porque não se trata de uma questão restrita à teoria, mas porque está implicada, o tempo todo, na realidade propriamente dita.

O valor do indivíduo presente no modelo educacional da escola convencional tornou-se obsoleto, uma ideia quase tão antiga quanto a do modelo de educação gerida pelo papel do preceptor. A ideia de indivíduo na forma escolar vigente é uma abstração: a escola só adquire sentido real diante de uma simultaneidade de alunos - a sala de aula em relação a uma turma. Com a obrigatoriedade dos acessos, o valor do indivíduo se dilui diante da lógica dos direitos universais. O professor, inserido nesse contexto, destina-se ao ensino de uma turma, e não, de um indivíduo. Esse quadro preliminar da instituição escolar convencional é requisito essencial para se refletir sobre a escolarização hospitalar. O que está em questão é o recente fenômeno da educação formal em ambientes alternativos.

O nivelamento dos alunos é inviável, devido às circunstâncias específicas do quadro de saúde em que se encontram. Com efeito, se, para a escola convencional, o ponto de partida é uma aproximação etária, em que a noção individual se anula em detrimento da coletiva, na escolarização hospitalar, a noção de indivíduo não só é o que irá estreitar o laço entre o professor e o aluno, mas também o que irá servir de orientação para o planejamento do trabalho. Sem o conhecimento prévio do estado de saúde do indivíduo, o trabalho hospitalar seria impossível.

Esses dados, além da questão da obrigatoriedade, apontam para essa experiência como uma fonte de busca por manter a vida. A experiência escolar, à medida que movimenta saberes herdados socialmente, traz uma carga de esperança positiva para essa população e tem um sentido tácito de remontar ao mundo das possibilidades e projetos, à compreensão reflexiva da existência social e à vida situada na tríade passadopresente-futuro, marcada, essencialmente, pela memória.

Entremos, agora, no ponto central de nosso debate: o problema epistemológico da escolarização hospitalar. De um lado, estão os valores educacionais que subsidiam a formação de professores: a origem, os métodos de ensino, as abordagens pedagógicas, o tempo escolar, a organização didática, os condicionantes históricos etc., e de outro, a situação do espaço hospitalar onde se estabelecerá a relação entre o professor e o aluno 
e são ressignificados os valores inerentes ao campo da saúde, da história hospitalar, da medicina, das representações da saúde, da doença, do temor à morte etc.

\section{A EXPERIÊNCIA ESCOLAR NO HOSPITAL}

Diversos autores refletiram sobre os sentidos da escola no ambiente hospitalar. Várias concepções alinhadas a origens epistemológicas distintas surgiram a esse respeito. Autores como Ceccim (1999), Fonseca (2003) e Ortiz (2002) admitem a experiência escolar e lhes atribui o sentido de "classes hospitalares". Para Matos e Mugiatti (2007, p.37), essa experiência é balizada pela concepção de "pedagogia hospitalar". Segundo as autoras, trata -se de um "processo alternativo de educação continuada que ultrapassa o contexto formal da escola, pois levanta parâmetros para o atendimento de necessidades especiais transitórias do educando, em ambiente hospitalar ou domiciliar". O conceito de Escola Móvel, de Covic (2005), carrega o caráter de flexibilidade que a experiência adquire no ambiente hospitalar. A aula, a partir desse conceito, desvincula-se de seu sentido tradicional. O tempo e o espaço adquirem sentidos totalmente distintos ao de uma aula tradicional. Dessa nova experiência, ficam resquícios simbólicos da representação de aula, que adquire uma conotação fragmentada: destitui-se da forma da aula historicamente construída e, em sentido lato, passa a ser a representação da aula, algo, a um só tempo, familiar e estranho. Tal é o aspecto que confere à questão o sentido da novidade e impõe um novo desafio. Nesse cenário, o papel do professor assume um sentido também específico e distante do modelo escolar pensado durante seu processo de formação.

A lógica que rege o formato da aula segue os pressupostos da escola de massas, portanto, do ensino simultâneo. Os aspectos mais particulares dos sujeitos, nessa perspectiva, devem ser suprimidos em detrimento da lógica do grupo. A singularidade, o ritmo, a expressão, o pensamento, os gestos e as ações são submetidos à lógica da constituição escolar. O sentido volta-se para o desenvolvimento do grupo. A idiossincrasia é solapada pelos dispositivos de coerção que adquirem sentidos nesse modelo escolar, pois há uma narrativa de conteúdos disciplinares que deve ser contemplada no tempo que se planejou para tal. A sequência segue, nesse modelo, um ritmo próprio. Aos alunos cabe o papel de acompanhá-lo de modo significativo, isto é, submetendo-se a provas que os autorizam a avançar. Mais recentemente, a partir do paradigma da progressão continuada, buscou-se superar a problemática relativa aos tempos da aprendizagem e, consequentemente, regularizar o fluxo de alunos nos anos 
escolares. O irrecusável argumento de que existem ritmos diversos de aprendizagem gerou um problema entre a forma como são trabalhados os conteúdos e as condições de aprendizagem. Embora diversos apontamentos tenham sido engendrados no sentido de superar essa dificuldade, como a implementação de ciclos no lugar de séries, deve-se reconhecer que tal modificação corresponde mais a um alinhamento político do que a uma garantia efetiva da aprendizagem.

Assim, ao refletirmos sobre a experiência da escolarização em ambiente hospitalar, uma nova distinção se impõe, pois não se trata apenas de uma desestruturação da ideia de aula e de escola nem de um retorno ao modelo elitista. $\mathrm{O}$ ponto central consiste na relação entre saúde e doença. O sentido le gal atribuído à educação cria uma zona indistinta entre a saúde e a doença: a educação, na condição de direito inalienável e com seu sentido de obrigatoriedade, coloca-se em um patamar que vai além do estado orgânico da criança/adolescente. Mas essa indistinção só adquire mais visibilidade quando a doença se torna parte desse período significativo da existência, como a fase escolar.

Quando a criança doente de câncer é submetida ao tratamento e internada no hospital por um período variável, cuja média vai, conforme Covic (2014), de oito meses a três anos, embora tenha a maioria das atividades corriqueiras da vida suspensas, adquire uma necessidade de ressignificar os sentidos corporais, simbólicos, afetivos, etc. Nesse contexto, a experiência escolar é particularmente significativa, já que a instituição escolar é parte fundamental dessa fase da vida. O trabalho docente, alinhado a essa peculiaridade, deveria, ao menos do ponto de vista teórico, ajustar-se às demandas que a situação impõe, pois, se não é, de fato, possível que o aluno enfermo tenha assegurada a vida escolar no formato da escola convencional, a escolarização hospitalar supre essa lacuna que é garantida na forma da lei ${ }^{5}$. Essa questão nos remete ao pensamento de Foucault e de Agamben acerca da biopolítica. Para Agamben (2004), há uma zona de indistinção entre a lei e a norma que é característica dos Estados modernos e que cria o que ele chama, tomando de empréstimo uma expressão de Walter Benjamin, de Estado de exceção permanente. Resta saber em que medida a experiência da escolarização hospitalar reflete essa condição contemporânea e de que modo a vida das crianças e dos adolescentes doentes é tratada e politizada por esses meios.

\footnotetext{
${ }^{5}$ Há uma ampla legislação que regula esse segmento. Destacamos, principalmente, a Resolução $n^{\circ}$. 41, de 13/10/1995, os Direitos da criança e do adolescente hospitalizados; as Diretrizes Nacionais para a Educação Especial na Educação Básica, de 1991, além da própria Constituição da República Federativa do Brasil de 1988.
} 
Deve-se considerar, todavia, que o direito à educação, pela força que a legislação lhe impõe e seu sentido de obrigatoriedade, adentra o espaço hospitalar obediente à legislação, porém sem a vigência que a põe de acordo com as normas da instituição escolar. Ocorre uma espécie de hibridação da lei sobre a norma, de modo que a própria vida $n u a^{6}$ se torna a própria lei.

Agamben refere que o Estado contemporâneo consiste em captar da vida biológica saúde, doença, sexualidade e trabalho, em um processo de inclusão dos mecanismos de poder e que, como se vê nesta passagem de Foucault,

[...] resulta daí uma espécie de animalização do homem posta em prática através das mais sofisticadas técnicas políticas. Surgem então na história seja o difundir-se das possibilidades das ciências humanas e sociais, seja a simultânea possibilidade de proteger a vida e de autorizar seu holocausto (Apud AGAMBEN, op. cit., p. 11).

O que estamos problematizando são os sentidos que a obrigatoriedade es colar produz na vida da criança e de adolescente enfermos. Trata-se de uma questão ainda pouco debatida nesse campo, embora se mostre como ponto crucial, se tomarmos como apoio o argumento de Agamben. A questão, como podemos notar, é o resultado do transcurso do desenvolvimento da escola moderna do início do século e sua estreita ligação com as correntes do pensamento coetâneo que culminaram, decisivamente, com a ideia de simultaneidade. A captação do homem por meio dessas técnicas políticas permite que nossa reflexão se encaminhe para outra articulação, porque, se o Estado de população descrito por Agamben é caracterizado pela destituição das fronteiras entre o indivíduo e a sociedade, a natureza e a cultura, a lei e a norma, a saúde e a doença etc., com efeito, não se pode deixar de compreender que a experiência da escolarização hospitalar adquire sentido de modo não menos impactante do que o da escola convencional. Isso, em certo sentido, anula (ou deveria anular) o exame acerca da qualidade inerente a tais experiências.

Assim, quer-se saber de que modo é possível compreender os demais sentidos decorrentes desse processo e que são simbolicamente representados pela ideologia do mundo corporativo. Desde o instante em que uma família passa a viver o drama de ter internado um filho ou parente próximo no hospital, depara-se com uma instituição fortemente marcada pelos aspectos legais relativos à vida e à restituição da saúde e da dignidade humana e com uma organização altamente ligada à lógica corporativa do

\footnotetext{
${ }^{6}$ Conceito central no argumento de Agamben (2011), na série de estudos Homo Sacer vida nua, e que implica, segundo o filósofo, a mera existência bioló gica do homem.
} 
mercado, própria do financiamento da instituição. Questões de cunho ético, mas que transbordam ao imaginário social constituem verdadeiros contrastes que, com ou sem consentimento, farão parte da vida dessa família. Exemplo disso é o $\mathbf{5}^{\mathbf{0}}$ andar do GRAACC, denominado de Centro Cirúrgico e Centro de Transplante de Medula Óssea Instituto Ronald McDonald. O que chama a atenção é o caráter insólito, quase surreal, de um dos nomes que mais enfaticamente produzem representações sobre as causas de o câncer ser o próprio título do andar. Atualmente, vale ressaltar, a OMS publicou um relatório que associa o uso exagerado da carne processada ao câncer, o que reforça, de modo incisivo, a produção de sentidos sociais sobre a relação apresentada e o contrassenso existente. Tal desnivelamento da lógica do bom senso, na visão de Geertz, revela o limiar da fronteira onde o direito se encontra subsumido à soberania das grandes corporações. Esse aparente contrassenso nos remete à observação que Freud fez no ensaio da década de 1930, O mal-estar na cultura, afirmando que o grande sentimento da civilização - e da modernidade - advém da angústia causada pela busca de soluções para os problemas que ela mesma engendrou. Isso corresponderia a afirmar, ao menos no campo das representações, que o produtor do câncer é o mesmo que produz sua cura (ou a financia). É como se, de modo alegórico, essa doença representasse o apogeu da criação destruidora da civilização, uma espécie de consagração da politização dos corpos, isto é, de sua indeterminação biológica. Cabe, aqui, uma advertência. Não partimos da suposição “errônea”, comorevelouMukherjee $(2012)^{7}$, de que o câncer seja causado pela civilização. Só quisemos apontar para um dos paradoxos resultantes do corpus de representações existentes em nossa sociedade.

O aprofundamento interpretativo das narrativas que são estabelecidas no convívio diário na instituição hospitalar, particularmente os sentidos produzidos na experiência da escolarização, é um desafio que se coloca nesse campo, porquanto se trata do esforço de desvelar a trama social presente nessa configuração social. Do ponto de vista metodológico, uma estratégia capaz de dar conta dessa problemática é o uso da etnografia. Vejamos por que no tópico seguinte.

\section{A PESQUISA ETNOGRÁFICA}

Diversos são os motivos que nos levam a essa busca: a) a atualidade do fenômeno; b) a tentativa de compreender as questões relacionadas aos dois campos

\footnotetext{
${ }^{7}$ Deacordo como autor, “ [...] médicos do Século XIX costumavam associar o câncer à civilização: o câncer, eles pensavam, era causado pela correria da vida moderna, que, de alguma forma, estimulava o crescimento patológico no corpo. A associação era correta, porém a causalidade não: a civilização não é causa do câncer, mas, ao prolongar a vida humana, ela o desvela"(MUKHERJEE,2012,p.65).
} 
profissionais, que se encontram ora em sentido convergente ora em sentido divergente; c) a tentativa de desvelar os sentidos imbricados no processo de escolarização hospitalar; d) o desejo de compreender a relação que se estabelece entre a escolarização e o aluno doente; etc. Os motivos, como se percebe, ampliam-se à medida que o fenômeno adquire uma plasticidade visual ou, como diria Durkheim, em que podem ser tratados como "coisa s" ( DURKHEIM, 1973). Deve-se ressaltar que a intenção da abordagem etnográfica não é somente de descrever a situação observada, mas de interpretar os sentidos menos óbvios que se manifestam na realidade estudada. Em seu texto clássico, A interpretação das culturas, Geertz ressalta o aspecto diferencial da etnografia como um recurso do trabalho antropológico. Segundo ele, não são os aspectos puramente técnicos da etnografia (a transcrição de textos, o levantamento de genealogias, a seleção de informantes, o registro em diário, etc.) que garantem seu empreendimento, mas o que ele, tomando de empréstimo uma noção de Gilbert Ryle, chamoude“descriçãodensa",istoé,umtipodeesforçointelectualqueadmiteriscose que não se limita ao aparente, à “descrição s uperficial”, mas que sugere sentidos e inferências que estão arraigados em uma "multiplicidade de estruturas conceituais complexas, muitas delas sobrepostas ou amarradas umas às outras, que são simultaneamente estranhas, irregulares e inexplícitas" (GEERTZ, 2008, p. 07). Ainda sobre a estratégia desse método, Geertz escreveu:

O problema metodológico que a natureza microscópica da etnografia apresenta é tanto real como crítico. Mas ele não será resolvido observando uma localidade remota como o mundo numa chávena ou como qualquer equivalente sociológico de uma câmara de nuvens. Deverá ser solucionado - ou tentar sê-lo de qualquer maneira através da compreensão de que as ações sociais são comentários a respeito de mais do que elas mesmas; de que, de onde vem uma interpretação não determina para onde ela poderá ser impelida a ir. Fatos pequenos podem relacionar-se a grandes temas, as piscadelas à epistemologia, ou incursões aos carneiros à revolução, por que eles são levados a isso. (GEERTZ, 2008, p. 17)

De acordo com esses apontamentos, o uso dessa abordagem deverá levar em conta esse "esforço intelectual" relativo à descrição densa. Esse aspecto tem a característica peculiar de escapar dos moldes mais rígidos de um desenho metodológico. A antropologia interpretativa, nesse sentido, adquire a noção de criação narrativa, ficcional. Aexigência poresse "esforçointelectual” de que nos fala Geertzrevela não só que as metodologias "duras" são pouco eficientes para se compreenderem os fenômenos culturais como também que esse tipo de investigação recai, por mais que 
outros métodos sejam utilizados, em criações ficcionais, em “ $\quad[. .$.$] alargamentos do$ universododiscursohumano" (GEERTZ, 2008).

Há uma ideia geral, ainda não confirmada, de um confronto epistemológico e político entre as duas dimensões de maior impacto nesse fenômeno: a saúde e a educação. O fato de aescolarização “existir” como prática no ambiente hospitalar gera problemas relativos ao capital simbólico dessas instituições e revelam as relações de poderaliexistentes.A“luta"peloespaço,umespaçoqueélegitimadoapenasnaforma da lei, não do fato, impregna as relações humanas da ideia de pertencimento e não pertencimento. A noção de "nós" e "eles" revela uma tensão entre campos historicamente constituídos e que, nesse caso de situação-limite, atravessa o destino do aluno doente. De um ponto de vista panorâmico, ainda que de modo hipotético, poderíamos supor a ocorrência de dois grupos cuja luta se dá pela: a) preservação do espaço, b) conservação do espaço; c) manutenção do poder, d) desestabilização do poder; e) legitimação da profissão etc., cujo ponto nevrálgico dessa equação culminaria, inevitavelmente, no corpo doente da criança/adolescente. Do ponto de vista do aluno, considerando sua condição de saúde que já não lhe é favorável, a consequência desse duplo direito adquire diversos sentidos, nem sempre positivos.

Ressalte-se, todavia, que essa característica que já soa interpretativa talvez se mostre velada pelas formas como o direito relativo a essas duas esferas é representado socialmente. $\mathrm{O}$ aspecto elementar do problema parece resultar desse enfrentamento entre dois campos solidamente constituídos que, na força da lei, veem-se obrigados a uma fusão em todas as suas dimensões relativas e cujo resultado implica um espaço onde uma tensão de forças distintas é projetada, finalmente, para o corpo da criança doente.

A interpretação do processo de escolarização em ambiente hospitalar situa a questão da educação formal como direito em uma situação-limite, isto é, quando a criança se encontra impossibilitada de frequentar a escola regular. A questão reside na tensão entre essa impossibilidade de frequência, decorrente da lógica do tratamento, e o caráter inalienável da educação como um direito garantido pela legislação. Essa relação foi discutida por Geertz, no ensaio $O$ saber local: fatos e leis em uma perspectiva comparativa. O emparelhamento entre a norma e o fato, segundo o antropólogo, requer que se reconheça a representação jurídica. Segundo ele,

a compreensão de que os fatos não nascem espontaneamente e de que são feitos, ou, como diria um antropólogo, são construídos 
socialmente por todos os elementos jurídicos, desde os regulamentos sobre a evidência, a etiqueta que regula o comportamento nos tribunais, e as tradições em relatórios jurídicos até as técnicas da advocacia, a retórica dos juízes, e os academicismos ensinados nas faculdades de direito, suscita questões importantes para uma teoria da administração da justiça que a considera, citando um exemplo representativo, como uma "série de emparelhamentos de configurações factuais com normas", ou "uma norma específica [...] pode ser sugerida por uma seleção das versões competitivas sobre o que aconteceu. (GEERTZ, 2014, p. 175)

Essa observação, do ponto de vista metodológico, adquire uma importância crucial, porquanto a questão do direito relativo à educação e à saúde não poderá ser vista como um conjunto de normas distantes do contato com a realidade propriamente dita. Ao contrário, essa relação que, em nosso estudo, incide sobre o sujeito em suas duas formas legais, deverá compor a realidade de modo abrangente.

\section{CONSIDERAÇÕES FINAIS}

Neste ensaio, o objetivo central consistiu em problematizar o uso da etnografia na pesquisa sobre a escolarização em ambiente hospitalar. Para tanto, orientamos o debate na perspectiva da constituição da escola moderna, do modelo republicano, no sentido de esclarecer alguns aspectos que, do ponto de vista epistemológico, incidem sobre o trabalho docente em ambiente hospitalar. Tal questão é fundamental para que se possa compreender esse cruzamento de fronteiras entre a saúde e a educação, justamente porque os dois campos encontram pontos de convergência e de divergência. Convergência, na medida em que a saúde, da mesma forma que a educação, insere-se na passagem do Século XIX para o XX, com um sentido de abertura para as massas. E divergência, porque o sentido público da saúde implica a prevenção, o controle e o tratamento.

Em outras palavras, se a educação orienta sua ação visando à massa através da instituição, o hospital o faz visando a um controle a distância, com as ideias de prevenção e de higiene, que são sustentadaspelodesenvolvimentodaestatística.“ [...] O movimento moderno da saúde pública surgiu ao mesmo tempo em que as sociedades estatísticas e por muitas razões similares" (BYNUM, 2011, p. 99). A partir da articulação entre saúde e educação, e mesmo que reconheçamos que tal articulação demande estudos mais aprofundados, pensar, principalmente, na experiência escolar dos profissionais de educação e dos alunos gravemente enfermos respeitando-se esses 
aspectos que ora aproximam, ora distanciam os dois campos, é fundamental na tarefa investigativa desse fenômeno.

Nesse sentido, deve-se considerar o espaço educacional em ambiente hospitalar não como uma simples quimera, mas como uma situação que impõe um novo desafio. Portanto, nada mais sugestivo do que a etnografia como um recurso metodológico para quem quer se aproximar desse contexto, ou dessa situação, a fim de empregar uma expressão de Goffman (1974). Situação em que a escola não é mais a mesma escola, isto é, não mais corresponde ao seu modelo estrutural, epistemológico, político, didático, curricular, espiritual; e o hospital, ao menos quando o aluno entra em contato com os domínios do conhecimento escolar, não é mais o hospital em seu modelo puro, um ambiente que reverbera a própria representação.

Nesse cruzamento, não há somente um fenômeno de encontro epistemológico, político, profissional, funcional, filosófico etc., mas também, sobretudo, um encontro de relações humanas que põe em movimento tais instâncias e que deixa em aberto perguntas ainda vagas no âmbito do conhecimento científico. Que experiência escolar o aluno tem nesse ambiente, distante de sua escola e dos seus amigos? Que relações humanas se estabelecem quando dois campos profissionais se cruzam por determinação da lei, isto é, quando a educação se torna uma demanda que transcende o espaço da escola convencional? Como é sentido, apreciado e compartilhado o trabalho dos professores nesse espaço entre fronteiras? O que constitui, finalmente, esse espaço complexo, novo, desafiador?

Essas questões, como vemos, são um tanto intrigantes, razão por que desafiam o pesquisador não a respondê-las de modo casuístico, dedutivo, prescritivo, mas a buscar um meio de interpretá-las a partir de sua imersão profunda na complexa teia onde o fenômeno se manifesta.

\begin{abstract}
In this article we discuss the ethnographic possibility on the perspective of interpretive anthropology, as a methodological resource for the research on hospital schooling. One reason that leads us to reflect on this strategy is due to the shortage of papers on the matter, that opens a gap and a request for interpretation of meanings related to this experience. Our preliminary understanding sees the phenomenon of hospital schooling as an intersection of the fields of health and education, which unfolds in its various dimensions: legal, structural, epistemological, professional, human, what brings up thus a sui generis breadth of human relations. In this regard, it is crucial to make a historical review of the conventional school, and of the hospital institution, for the understanding of this intersection will provide us with interpreting the social forms that are there
\end{abstract}


materialized, specifically those relating to the experience of schooling in a stranger

environment than the usual.

KEYWORDS: Hospital schooling. Ethnography. Interpretive anthropology. Law.

\section{REFERÊNCIAS}

AGAMBEN, Giorgio. O que é contemporâneo? e outros ensaios. Chapecó, SC: Argos, 2010. 92p. $192 \mathrm{p}$.

O poder soberano e a vida nua I. Belo Horizonte, MG: Ed. UFMG, 2010.

Estado de exceção. São Paulo: Boitempo, 2004. 140p.

AMARAL, P. D. Saber e prática docente em classes hospitalares: um estudo no município do Rio de Janeiro. 2001. 113 f. Dissertação (Mestrado em Educação) Universidade Estácio de Sá, Rio de Janeiro. 2001.

ARENDT, Hannah. Entre o passado e o futuro. São Paulo: Perspectiva, 1972. 344p.

Origens do totalitarismo. São Paulo, Companhia das Letras, 1989.

BRASIL. Constituição da República Federativa do Brasil. Brasília: Imprensa Oficial, 1988.

Diretrizes Nacionais para a Educação Especial na Educação Básica. Resolução CNE/ CBE $n^{\circ} 2$ de 11/09/01. Diário Oficial da União $n^{\circ} 177$, Seção 1E de 14/09/01, pp.39- 40. Brasília: Imprensa Oficial, 1991.

. Direitos da criança e do adolescente hospitalizados. Resolução n. ${ }^{\circ} 41$, de 13/10/ 1995. Brasília: Imprensa Oficial, 1995.

BARROS, Alessandra Santana Soares. A prática pedagógica em uma enfermaria pediátrica: contribuições da classe hospitalar à inclusão desse alunado. Revista Brasileira de Educação 12 (set/nov): 84-93. 1999.

BOURDIEU, Pierre. A economia das trocas simbólicas. São Paulo: Perspectiva, 2011. $361 p$.

BYNUM, William. História da Medicina. Porto Alegre, RS: L\&PM, 2011. 192p.

CALEGARI, A. M. As inter-relações entre educação e saúde: implicações do trabalho pedagógico no contexto hospitalar. 2003. 141 p. Dissertação (Mestrado em Educação: Aprendizagem e Ação Docente) - Universidade Estadual de Maringá, Maringá. 2006.

CECCIM, R. B. Classe hospitalar: encontros da educação e da saúde no ambiente hospitalar. Pátio Revista Pedagógica. Porto Alegre, ano 3, n. 10, p.41-44, ago/out. 1999.

COVIC, A, N; OLIVEIRA, Fabiana Aparecida de Melo. O aluno gravemente enfermo. São Paulo: Cortez, 2011. 199p.

COVIC, A. N. Atendimento pedagógico hospitalar: convalidando uma experiência e sugerindo ideias para a formação de educadores. Dissertação de Mestrado: PUC-SP, 2003. 
COVIC, A. N. et al. Estudo do desenvolvimento escolar de alunos da educação básica que passaram pelo tratamento oncológico. In: Anais do XIV Congresso Brasileiro de Oncologia Pediátrica: Brasília, 2014.

. Escola Móvel: uma vivência de classe hospitalar brasileira. Anais do XX Congresso Latino-americano de Oncologia Pediátrica/ II Encontro Continental da Sociedade Internacional de Oncologia Pediátrica, 2005, Campo Grande/MS. XX Congresso Latino-americano de Oncologia Pediátrica. Campo Grande: SES, 2005. v. Único. p. 64-64.

DURKHEIM, Émile. As regras do método sociológico. (Coleção os Pensadores). São Paulo: Abril S.A., 1973. 165p. $\overline{465-504 .}$.

O suicídio. São Paulo: Abril Cultural, 1973. (Coleção Os Pensadores, v. 33). p.

Elias, N. (1990). O processo civilizador (uma história dos costumes). Rio de Janeiro:

Zahar Editor.

FERREIRA, Mayara Kelly Moura et al. Criança e adolescente cronicamente adoecidos e a escolarização durante a internação hospitalar. Trab. educ. saúde [online]. 2015, vol.13, n.3, pp.639-655. ISSN 1678-1007. http://dx.doi.org/10.1590/1981-7746-sol00001.

FOUCAULT, M. “A vontade de saber”. História da sexualidade. Vol 1. Rio de Janeiro: Graal, 1977. 151p.

FONSECA, E. S. Atendimento escolar no ambiente hospitalar. São Paulo: Memnon Ed. Científicas, 2003.

FREUD, Sigmund. O mal-estar na cultura. Porto Alegre: L\&PM Pocket, 2010.192p.

FUNGHetTo, S. S. A doença, a morte e a escola. Um estudo através do imaginário social. 1998. 86 p. Dissertação (Mestrado em Educação) - Centro de Educação, Universidade Federal de Santa Maria, Santa Maria. 1998.

GABARDO, A. A. Classe hospitalar: aspectos da relação professor-aluno em sala de aula de um hospital. 2002. 50 f. Dissertação (Mestrado em Psicologia) - Centro de Filosofia e Ciências Humanas, Universidade Federal de Santa Catarina, Florianópolis. 2002.

GEERTZ, Clifford. O saber local: novos ensaios em antropologia interpretativa. Petrópolis, RJ: Vozes, 2014. 238p.

GOFFMAN, Ervin. Manicômios, prisões e conventos. São Paulo: Perspectiva, 1974. $312 p$.

HABERMAS, J. Conhecimento e interesse (J. Heck, trad.). Guanabara. Rio de Janeiro: 1987.

HABERMAS, J. Teoria do Agir Comunicativo. São Paulo: Martins Fontes, 2012. $704 p$.

HOLANDA, Eliane Rolim de COLLET, Neusa. Escolarização da criança hospitalizada sob a ótica da família. Texto contexto - enferm. [online]. 2012, vol.21, n.1, pp.34-42. ISSN 0104-0707. http://dx.doi.org/10.1590/S0104-07072012000100004.

LÉVI-STRAUSS, C. Totemismo hoje. Petrópolis: Vozes, 1976.

As estruturas elementares do parentesco. Petrópolis, Vozes, 1976.

Revista Temas em Educação, João Pessoa, v.26, n. 1, p. 70-85, jan.-jun. 2017. 
MARCHESAN, E. C; Bock; A. M. B, Petrilli; A. S, Covic, A. N \& Kanemoto, E. (2009). A não escola: os sentidos atribuídos à Escola e ao professor hospitalares por pacientes oncológicos. Revista Ciência e Profissão, 29(3), 476-93.

MATOS, Elizete Lúcia Moreira; MUGIATTI, Margarida Maria Teixeira de Freitas. Pedagogia hospitalar: a humanização integrando educação e saúde. 2. Ed. Petrópolis, RJ: Vozes, 2007. 181p.

MUKHERJEE, Siddhartha. O imperador de todos os males. São Paulo: Companhia das Letras, 2012. 634p.

OLIVEIRA, F. P. M. Projeto pedagógico hospitalar escola-móvel - Aluno específico: cultura escolar e debate acadêmico (1989-2008). 2009. 287 f. Dissertação (Mestrado em Educação) - Universidade Estadual de Campinas, Campinas, 2010.

ORTIZ, L. C. M. Classe hospitalar: reflexões sobre uma práxis educativa. 2002. 83 f. Dissertação (Mestrado em Educação) - Universidade Federal de Santa Maria, Santa Maria. 2002.

PETITAT, André. Produção da escola, produção da sociedade: análise sóciohistórica de alguns momentos decisivos da evolução escolar no Ocidente. Porto Alegre: Artes Médicas, 1994.

PETRILLI, A. S. (Org.) et al. Terapêutica e prática pediátrica. São Paulo: Atheneu, 2000. p. 1251-1334. 18

ROUSSEAU, Jean-Jacques. Emílio ou Da Educação. São Paulo: Martins Fontes, 2014. $711 \mathrm{p}$.

SALDANHA, Gilda Maria Maia Martins e SIMÕES, Regina Rovigati. Educação escolar hospitalar: o que mostram as pesquisas?. Rev. bras. educ. espec. [online]. 2013, vol.19, n.3, pp.447-464. ISSN 1413-6538. http://dx.doi.org/10.1590/S141365382013000300010 .

SCHNEIDER, Karine Larissa Knaesel e MARTINI, Jussara Gue. Cotidiano do adolescente com doença crônica. Texto contexto - enferm. [online]. 2011, vol.20, n.spe, pp.194-204. ISSN 0104-0707. http://dx.doi.org/10.1590/S0104-07072011000500025.

TITIEV, M. Introdução à antropologia cultural ( $5^{\mathrm{a}}$ ed.). Coimbra: Fundação Calouste Gulbenkian, 1966.

XAVIER, Thaís Grilo Moreira; ARAUJO, Yana Balduíno De; REICHER T, Altamira Pereira dos Santos e COLLET, Neusa. Classe hospitalar: produção do conhecimento em saúde e educação. Rev. bras. educ. espec. [online]. 2013, vol.19, n.4, pp.611-622. ISSN 1413-6538.

ZARDO, S. P. O desenvolvimento organizacional das classes hospitalares do RS: uma análise das dimensões econômica, pedagógica, política e cultural. 2007. $214 \mathrm{f}$. Dissertação (Mestrado em Educação: Educação Especial) - Centro de Educação, Universidade Federal de Santa Maria, Santa Maria.

$/ 02 / 2017$

$/ 03 / 2017$ 